\title{
Petrological evidence in support of the death mask model for Ediacaran soft-bodied preservation in South Australia
}

Alexander G. Liu, Sean McMahon, Jack J. Matthews, John W. Still

and Alexander T. Brasier

\section{SUPPLEMENTARY FIGURES}
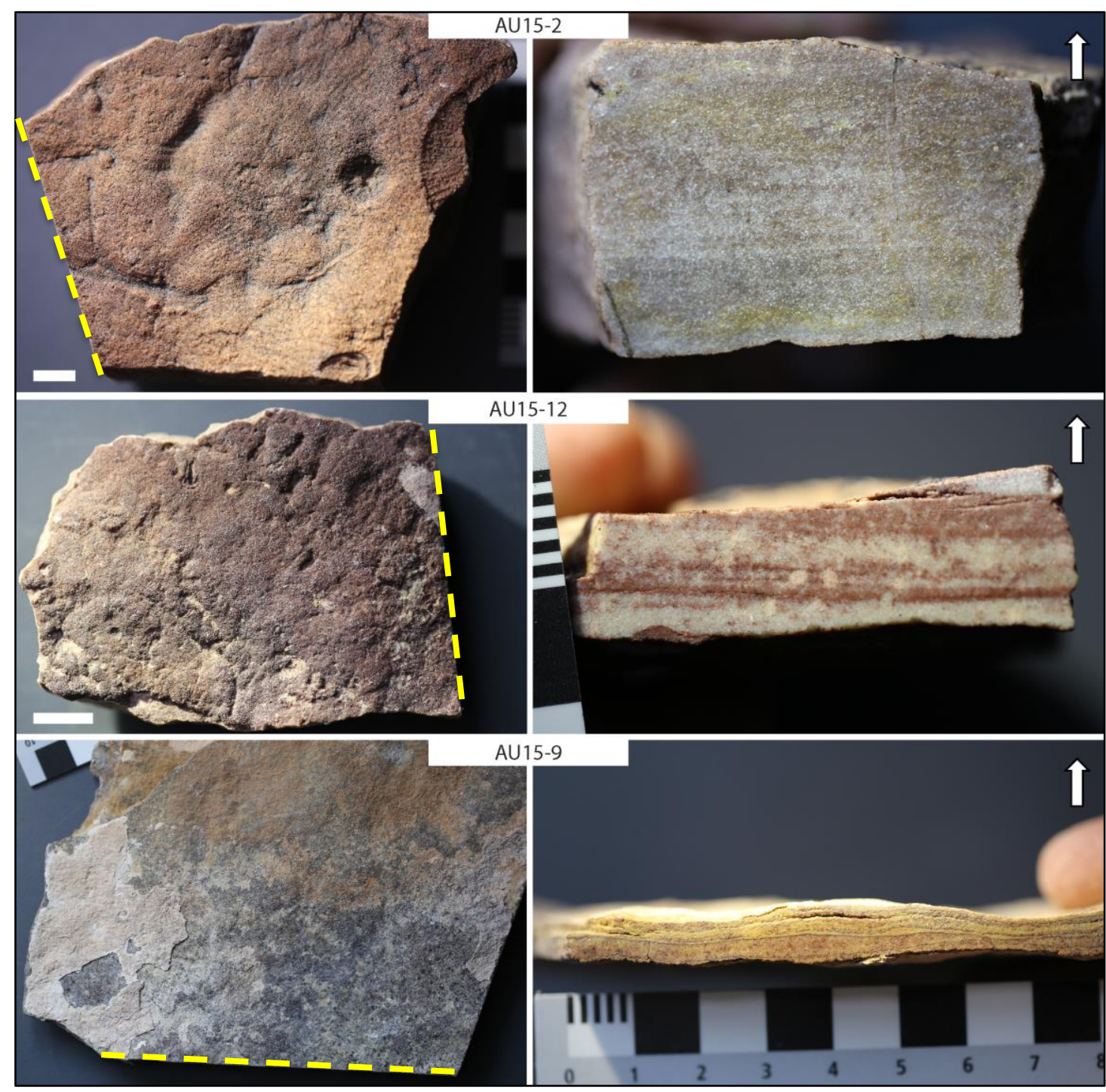

Figure S1. Hand specimens from which the figured thin sections figured in the manuscript originate. AU15-2 originates from the Oscillation-Rippled Sandstone Facies of the Ediacara Member at One Tree Hill, Nilpena. AU15-9 and AU15-12 were collected from North Ediacara Conservation Park, in what are interpreted as FlatLaminated Linguoid-Ripple Sandstone Facies of the Ediacara Member (after Tarhan et al. 2017). At left in each image is a view of the fossil-bearing bed sole. Dashed yellow lines indicate line of section. All specimens were collected from float. Scale bars $=10$ $\mathrm{mm}$. 


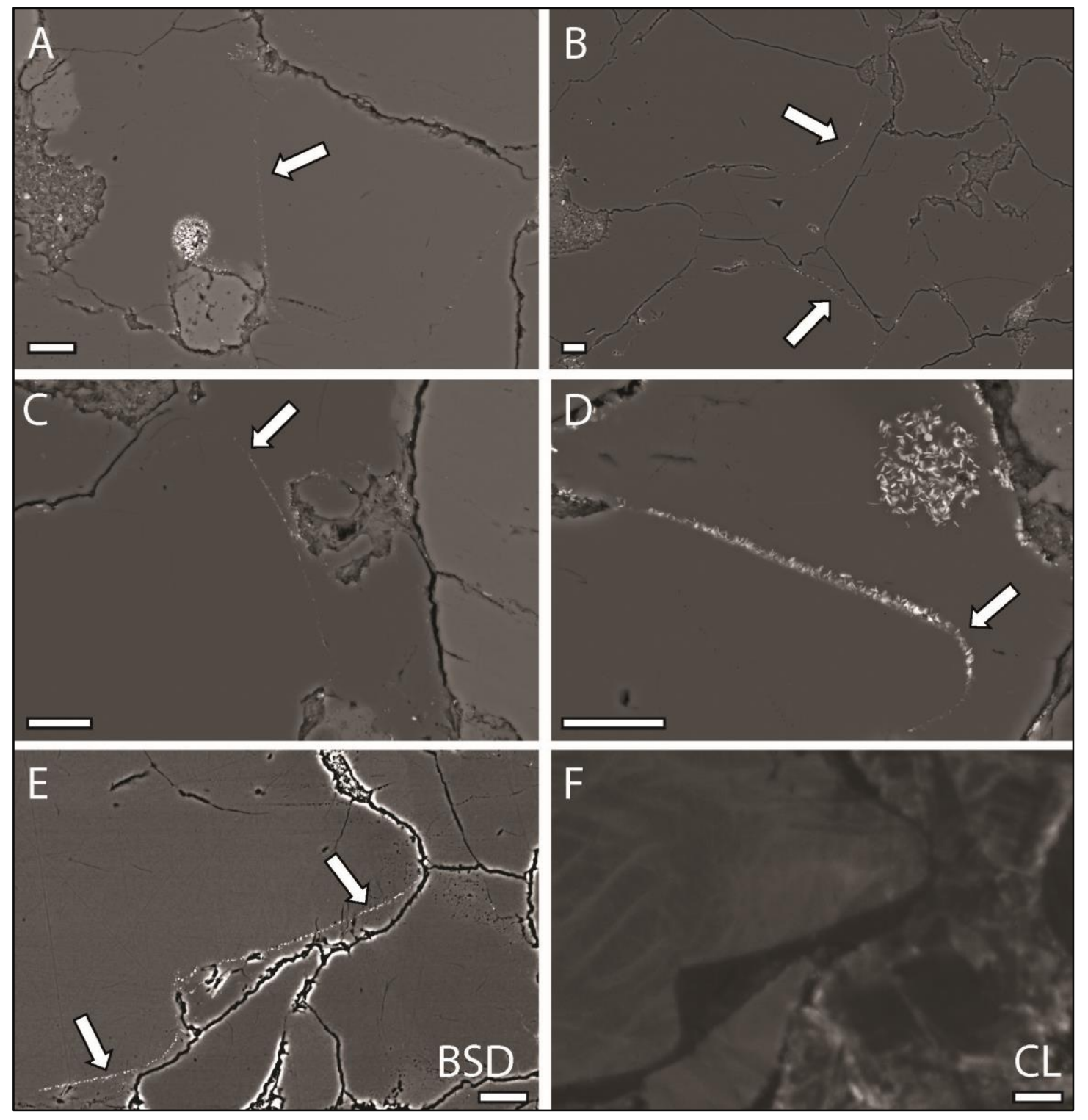

Figure S2. Scanning electron micrographs of iron oxides associated with the sole of sample AU15-12. (A-E) Fe-oxides (white) arranged as framboids (A, D), or as bands (arrowed) running through the middle of optically continuous quartz crystals. (F) Cathodoluminescence image of the region in E), revealing that the Fe-oxide bands are following original grain boundaries, and are overgrown by a later quartz cement. $\mathrm{Fe}-$ oxide microcrystals in both bands and adjacent framboids are of comparable size and composition. Scale bars $=10 \mu \mathrm{m}$. 


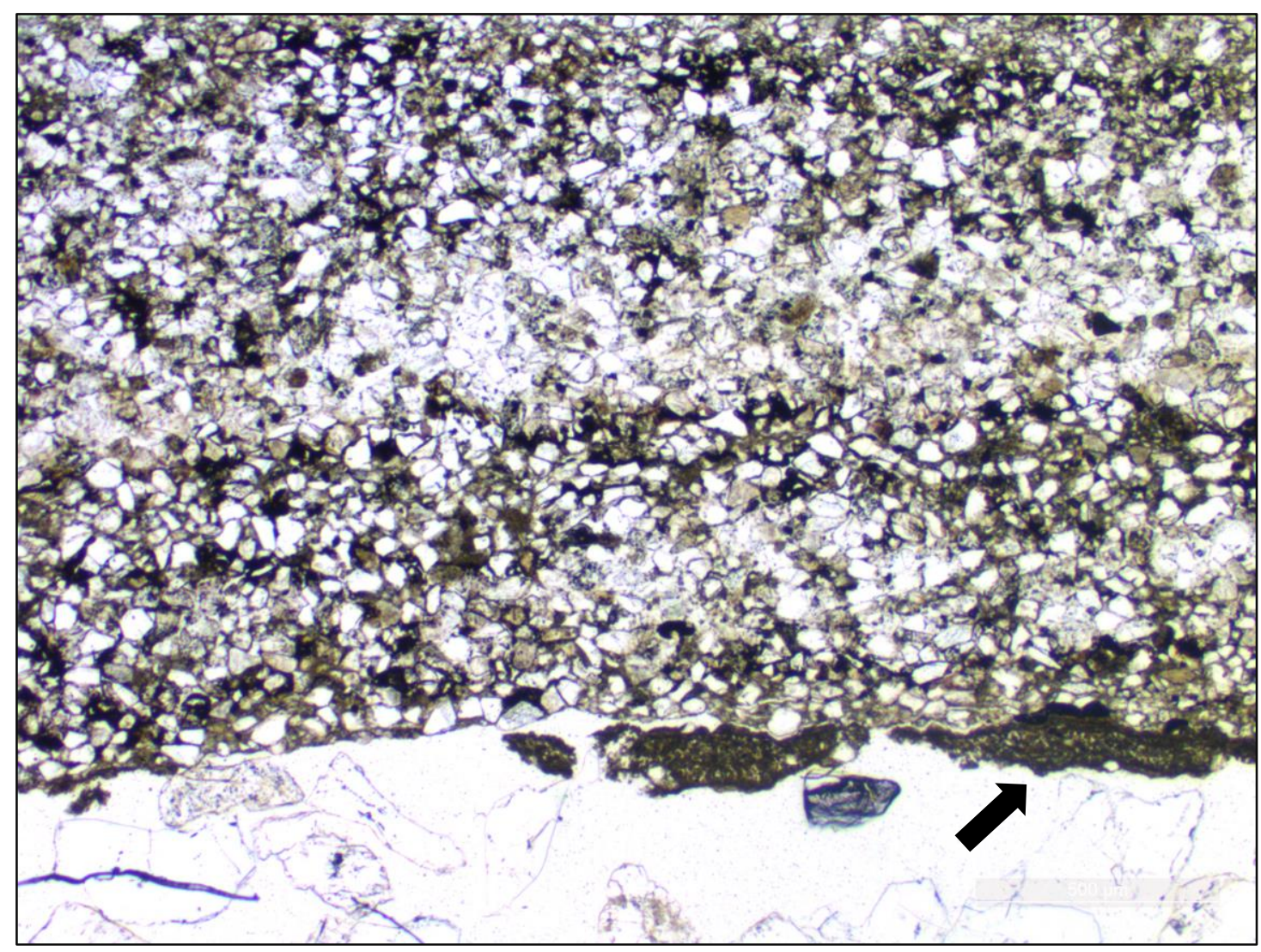

Figure S3. Thin section AU15-9B in plane polarised light, showing the bed sole with an adhering fine-grained, clay-rich layer (arrowed), and abundant iron oxides (black) present at the interface at which fossils are preserved (best seen at the lower right of the image). Scale bar $=500 \mu \mathrm{m}$. 

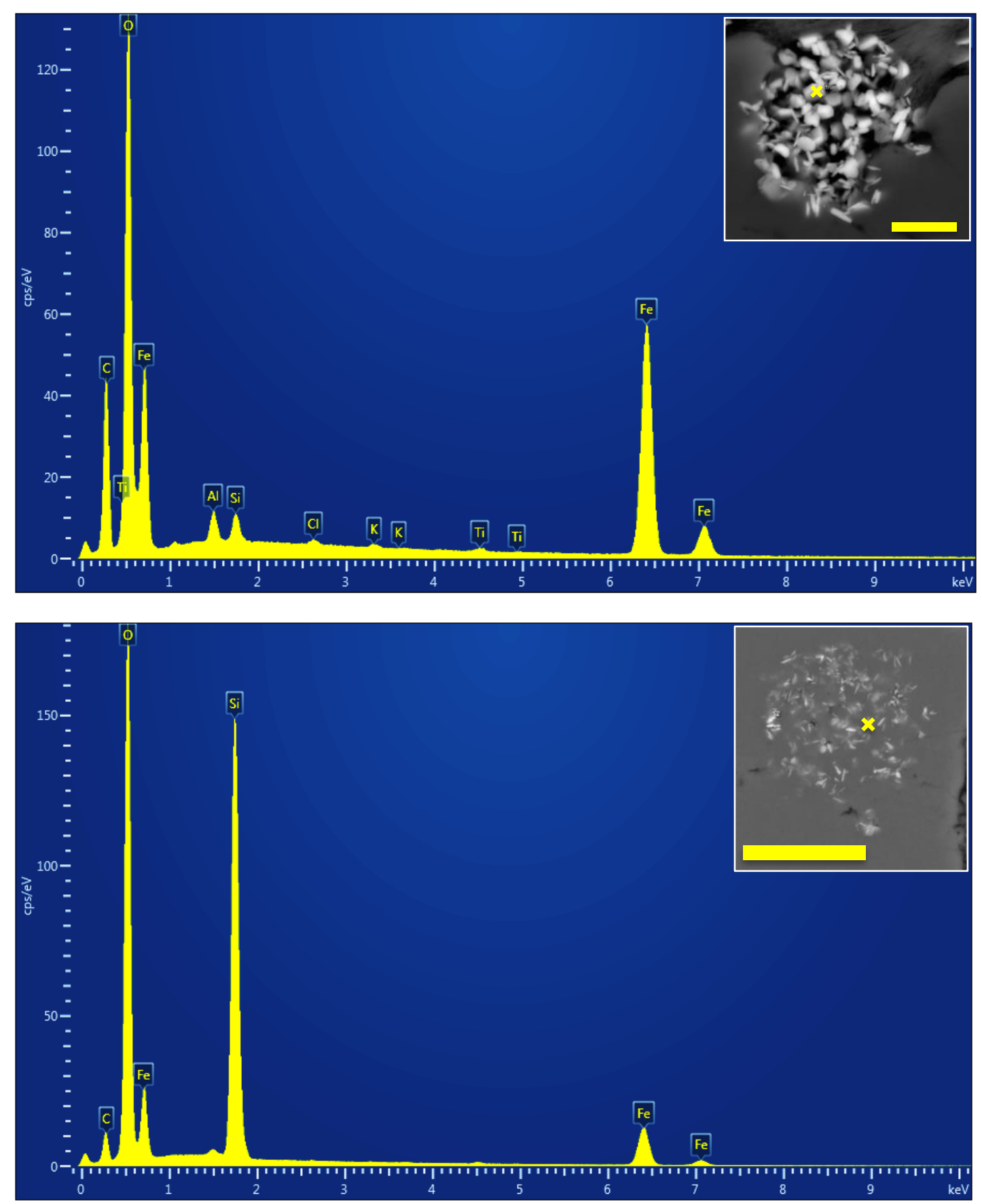

Figure S4. EDS spectra confirming the iron-oxide composition of framboids in the Ediacara Member at North Ediacara Conservation Park, close to the fossil-bearing bed sole of sample AU15-12. The sample was carbon-coated. Top: Framboid (also illustrated in Fig. 3D) that is unusually well expressed (scale bar $=2.5 \mu \mathrm{m}$ ). Bottom: Framboid (also illustrated in in Fig. 3B) encased in silica, which is optically transparent but masks the BSE image and EDS spectrum. 

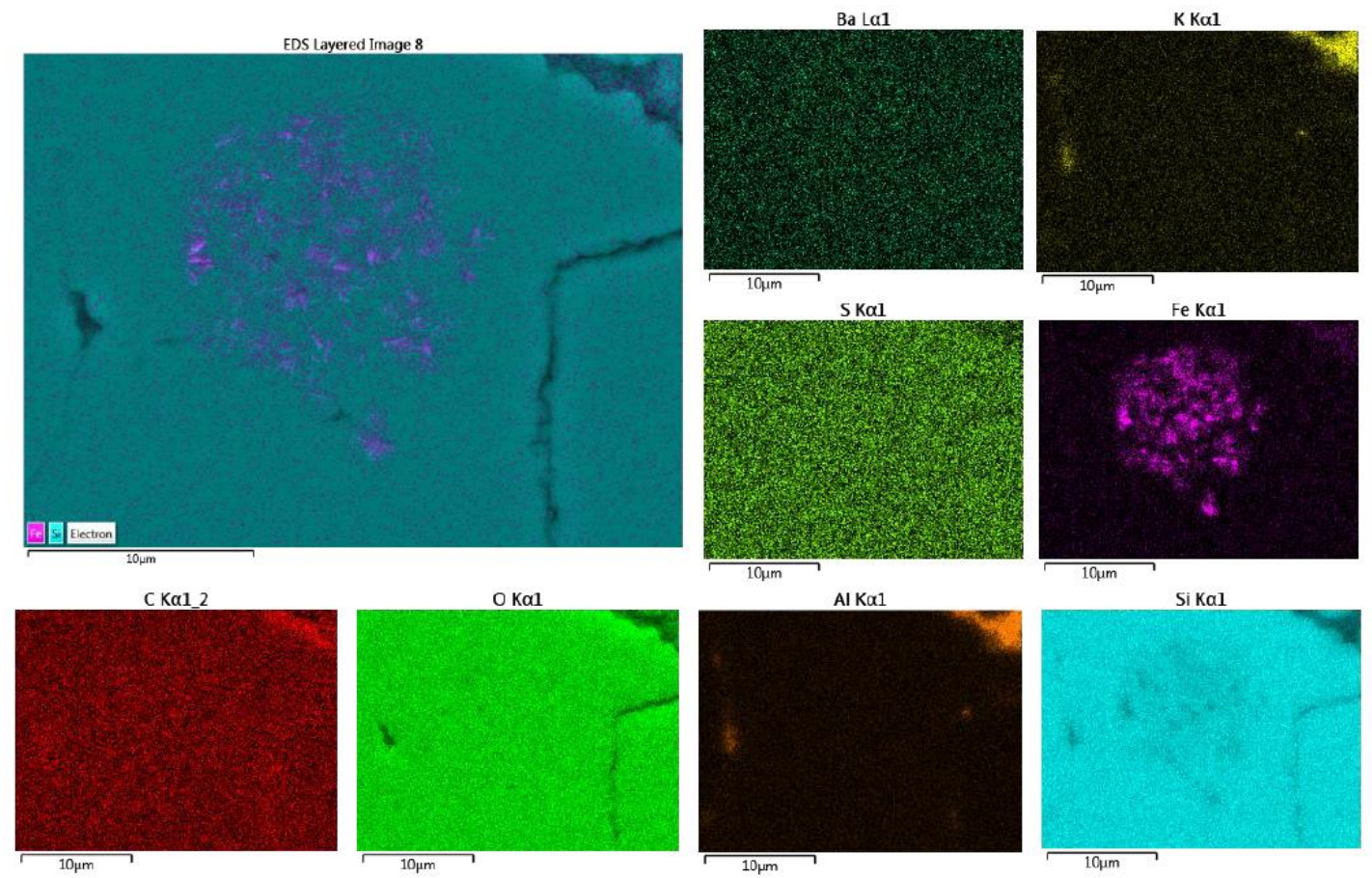

Figure S5. EDS maps revealing the elemental composition of the framboid illustrated in Figures 3B and S4B, from thin section AU15-12. Brighter colour intensities indicate higher elemental counts. 


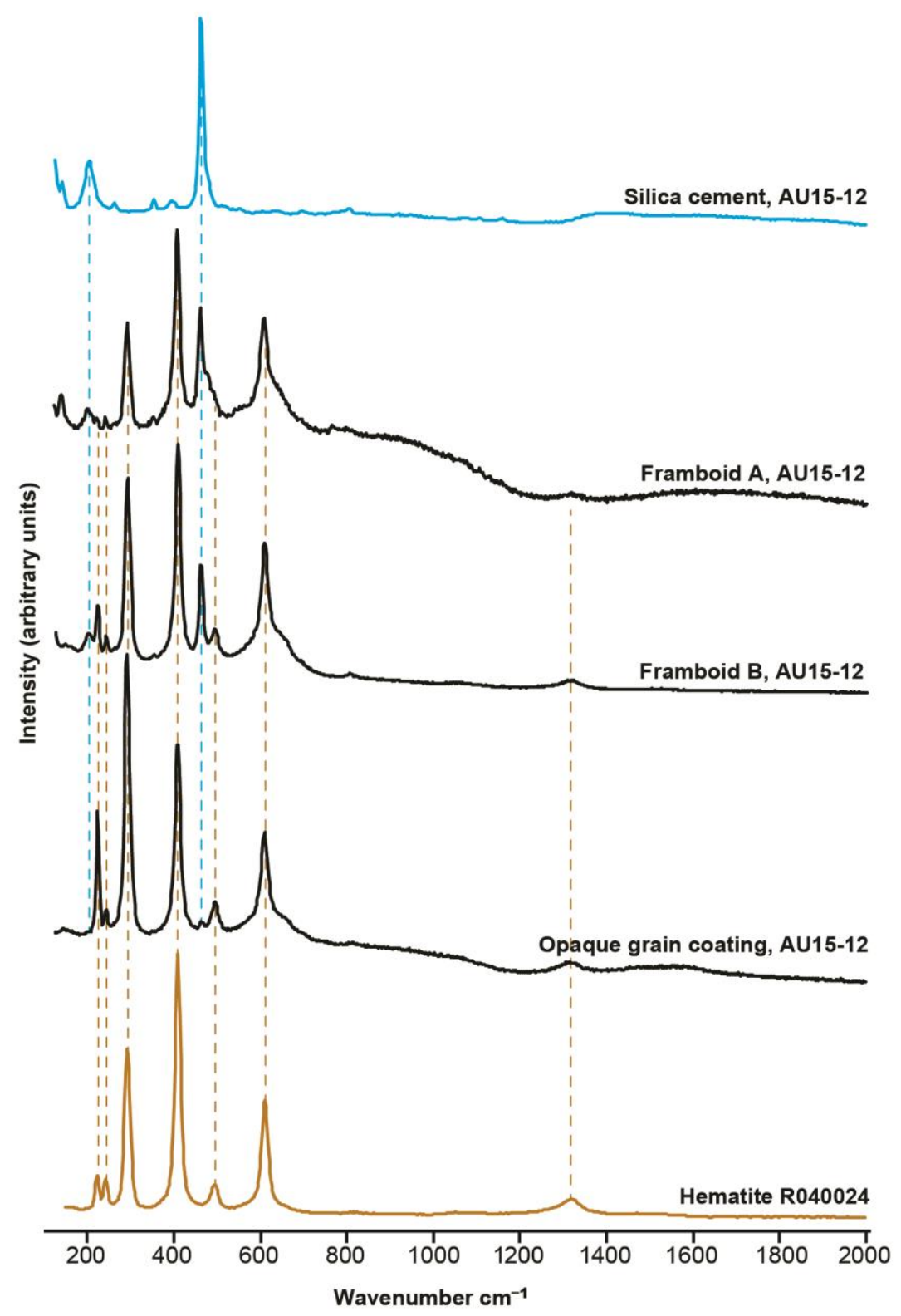

Figure S6. Raman spectra taken from silica cement, two framboids, and an opaque grain coating in thin section AU15-12 from the Ediacara Member at North Ediacara Conservation Park, close to fossil-bearing bed soles. Comparison with a reference spectrum (hematite R040024; University of Arizona Mineral Museum 12904; spectrum obtained from the RRUFF database; Lafuente et al., 2015) confirms that the framboids and grain coating are composed of hematite (brown dashed lines); the remaining spectral peaks are contributed by the silica cement (blue dashed lines).

\section{SUPPLEMENTARY REFERENCE}

Lafuente, B., Downs, R.T., Yang, H., and Stone, N., 2015, The power of databases: the RRUFF project. In: Highlights in Mineralogical Crystallography, T. Armbruster and R.M. Danisi, eds. Berlin, Germany, W. De Gruyter, pp. 1-30. 